\title{
POPULATING A LIBRARY OF REUSABLE H-BOMS: ASSESSMENT OF A FEASIBLE IMAGE BASED MODELING WORKFLOW
}

\author{
C. Santagati ${ }^{* a}$, M. Lo Turco ${ }^{\text {b* }}$, G. D’Agostino ${ }^{a}$ \\ a Department of Civil Engineering and Architecture, Università di Catania, Via Santa Sofia n. 64 95123, Catania, Italy- \\ cettina.santagati@dau.unict.it; graziana.dagostino@gmail.com \\ b Department of Architecture and Design, Politecnico di Torino, viale Mattioli n.39 10125, Torino, Italy- \\ massimiliano.loturco@polito.it
}

Commission II

KEY WORDS: Laser scanning, H-BIM, digital cultural heritage, SfM, Level of Accuracy, semantic modeling

\begin{abstract}
:
The paper shows the intermediate results of a research activity aimed at populating a library of reusable Historical Building Object Models (H-BOMs) by testing a full digital workflow that takes advantages from using Structure from Motion (SfM) models and is centered on the geometrical/stylistic/materic analysis of the architectural element (portal, window, altar). The aim is to find common (invariant) and uncommon (variant) features in terms of identification of architectural parts and their relationships, geometrical rules, dimensions and proportions, construction materials and measure units, in order to model archetypal shapes from which it is possible to derive all the style variations. At this regard, a set of $14^{\text {th }}-16^{\text {th }}$ century gothic portals of the catalan-aragonese architecture in Etnean area of Eastern Sicily has been studied and used to assess the feasibility of the identified workflow.

This approach tries to answer the increasingly demand for guidelines and standards in the field of Cultural Heritage Conservation to create and manage semantic-aware 3D models able to include all the information (both geometrical and alphanumerical ones) concerning historical buildings and able to be reused in several projects.
\end{abstract}

\section{INTRODUCTION}

Our cultural heritage is increasingly threatened by natural, environmental and anthropic risks. We could consider earthquakes, climate changes and terroristic attacks, only to name a few, trying to envision future scenarios where all the efforts of the communities should be projected into the management of existing 3D virtual database that recover all the information on an historical tangible good.

In this direction, last decades have seen several projects aimed at the 3D digitization of artifacts exploiting the advantages that current 3D technologies make available. Nevertheless, in spite of the performances and effectiveness of these technologies, the provided output (point cloud, mesh) is not an intelligent model, but it is constituted by a large number of points that are ontologically indistinct until they are semantically interpreted. The need for achieving semantic-aware models (enriched with available geometric and alphanumeric data) led the European Commission to consider a specific call under H2020 program (Reflective 7: Advanced 3D modelling for accessing and understanding European cultural assets) with the aim of solving this gap (Bonsma et al., 2016; Phillips et al., 2016) and moving towards standards and protocols specifically centered on Cultural Heritage domain.

Considering historical buildings documentation and management, the Building Information Modeling (BIM) approach, already used in Architectural Engineering and Construction (AEC) field, seems to be the best solution in the field of Cultural Heritage Conservation to create and manage semantic-aware 3D models able to include all the information in a unique 3D model. The major difficulties encountered by academics and practitioners is the use of commercial BIM platforms to fulfill this important task. Therefore, the fact that these platforms were born to be used for new constructions, it implies that there is a lack of libraries of historical buildings components that needs to be filled up.
The paper shows the intermediate results of a research activity aimed at populating a library of reusable Historical Building Object Models (H-BOMs) by testing a full digital workflow that firstly takes advantages from using Structure from Motion (SfM) models; furthermore it is centered on the interpretation of the architectural element (portal, window, altar) in order to go back to the archetypal shapes (identifying the geometrical rules, with a particular regard to the invariant and invariant features) from which it is possible to derive all the style variations.

The database linked to the BIM model can be populated by many other information, not only related to the geometric definition of the $3 \mathrm{~d}$ model. Some samples could be the collection of ancient drawings available on specific historical paper archives, the finding of old and more recent pictures, data related to the decays including observations, material description and technicalities useful to figure out future intervention, only to name a few.

At this regard, a set of $14^{\text {th }}-16^{\text {th }}$ century gothic portals has been studied. They constitute a recurrent typology of the CatalanAragonese architecture in Etnean area of Eastern Sicily. These portals are usually made by locally available materials such as the lava stone together with white limestone, which leads to a distinctiveness bi-chromatism typical of these areas.

The remainder of the paper is organized as follows: Section 2 will be dedicated to the analysis of the state-of-the-art, with a specific regard to the recent image-based techniques and the subsequent activities to convert point clouds into semantic aware objects. Section 3 describes the methodology and the identified workflow centered on knowledge base data interpretation. Section 4 deals with workflow assessment on a chosen case study; the results obtained are discussed in Section 5 , then concluding remarks and future activities (Section 6) complete the work. 


\section{CURRENT DEVELOPMENT}

Cultural heritage sites and our valuable historical architectural heritage require high-resolution 3D models to achieve a significant added value from their digitalization (Quattrini et al., 2015).

These models are increasingly available thanks to rapid technological progress in the field of acquisition, especially for image-based methods that work with digital photogrammetry (Chiabrando, Spanò, 2013). The low costs of these techniques as well as their attractive visual quality have led many researchers and professionals to invest their energies and resources in several tests that have shown the reliability of structure from motion (SfM) techniques for architectural elements where other techniques (such as terrestrial laser scanning) are costly, not sufficiently dense, or not easy to access (Kersten, Lindstaedt, 2012).

At these days, as for image-based modeling, the accurate and detailed reconstruction of geometric models of real objects has become a common process: as a matter of fact, the use of digital technologies has completely changed and improved the working methods also related to the representation and modeling phases in the architectural heritage domain (Santagati, Lo Turco, 2016).

Although data collection technologies are now very efficient and automated, the processing of this data is still very timeconsuming (Dore, Murphy, 2014).

In literature, we find several studies (Murphy et al., 2013) that address the crucial transition regarding the conversion from the point cloud to the intelligent parametric object, introducing the concept of Level of Accuracy (LoA). In other words, the point cloud can be considered a digital copy of the object that preserves its geometric features (irregularities, deformations, etc).

Going more into depth, the "as-built" BIM characterization involves three aspects which allow one to pass from a point cloud to a structured semantic-aware 3D model: shapes and parametric intelligence (Hichri et al., 2013) relations, and attributes (Tang et al., 2010). Regarding the shape of the object, it can be classified according to some specific variables:

- flexibility (parametric or not-parametric features);

- global or local.

The proposed activity refers to local models, intended as specific building components as the portals illustrated in Figure 1 , in order to create new building components that could be reused in other projects (Biagini et al., 2016, Garagnani, Manferdini, 2013). The resulting virtual components will be made up of very different elements (2D elements consisting of profiles, surface-based models, parametric archetypes from which the different variants can be obtained). These elements will be semantically enriched by the alphanumeric database consisting of useful parameters for cataloging and managing heterogeneous data involving different knowledge (archive documents, historical and recent images, acquisition and metric survey techniques, materic information and the description of degradation pathologies (Lo Turco et al., 2017) just to mention the main ones. These elements (moldings, profiles, symbols, and so on) become the architectural vocabulary, after having recognized the different elements and proceeding from general to particular: the architectural elements have been gradually destructured up to the moldings - the atoms of the architectural lexicon (Lo Buglio, De Luca, 2012) through a conceptual abstracted process where geometry is a tool to decode the complexity of reality.

The whole composition relates to a linguistic structure, offering a basis for analysis and understanding (Clarke, Crossley, 2000).

\section{METHODOLOGY}

The developed workflow, previously tested on a single architectural element (Santagati, Lo Turco, 2016), is aimed at obtaining libraries of reusable $\mathrm{H}-\mathrm{BOMs}$ to be used in several projects and is centered on historical architectural language knowledge base. The workflow is fully digital driven and foresees the following steps:

- identification of a set of historical architectural elements (portals, windows, altars) belonging to a stylistic typology;

- 3D data acquisition and processing (considering the size of the architectural elements, low cost Image-Based Modeling techniques can be exploited);

- study of the architectural element according to its geometrical and stylistic features, destructuring it into simpler elements and identifying the hierarchies and the relationships between the parts.

- metrological/modular study aimed at the verification and subsequent quantification of regular modular grids or other geometric proportional rules that give proportions and link the individual parts to the whole (for example ratio between width and height in the openings; modular relationship between the members of architectural order, ect.). Furthermore, the metrological study will put in relation the achieved results with the metrical units used in the past.

- identification of the common and variant features of the analyzed elements, in order to find generalizing geometric rules and variable features, i.e. according to used materials, geometrical profiles that will be used in the next modeling step.

- Historical Building Object Modeling according to the previous steps results using nested families or all-in-one families (the parametric component are called "families" according to Revit's naming procedure);

- setting of the different Levels of Geometry (LoG, related to purely Graphic Detail) according to the scale of representations and Levels of Information (LoI) here intended as the rational collection of several information useful to describe not geometrical features to be recovered in the BIM component

\section{WORKFLOW ASSESSMENT}

To assess our workflow, a set of portals of the Etnean area (eastern Sicily) realized during the Catalan-Aragonese domination in Sicily (end of $13^{\text {th }}-16^{\text {th }}$ century) has been studied with the aim at identifying recurrent geometries and stylistic features (figure 1).
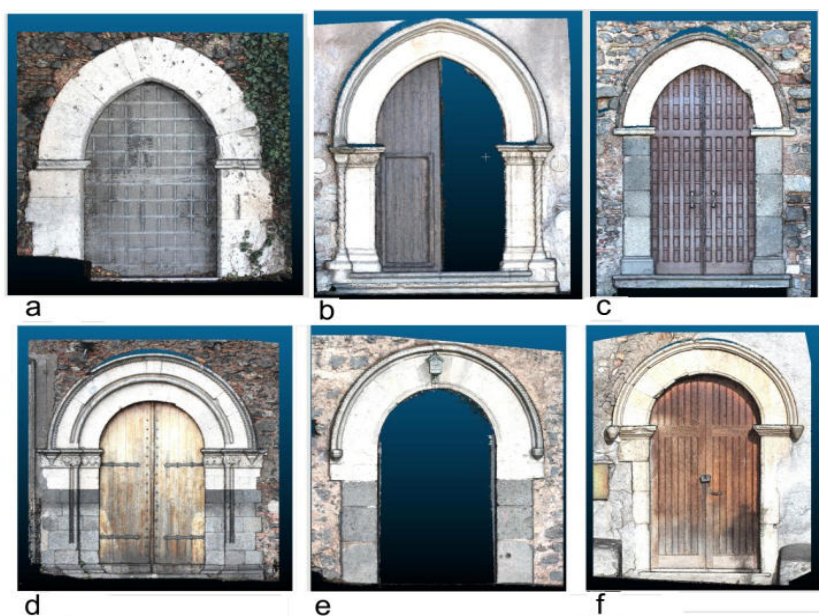

Figure 1. Catalan-Aragonese gothic portal point clouds: a) lateral portal of S. Antonio Abate church (Mascalucia); b) S. Maria di Josaphat church (Paternò); c) S. Francesco convent (Paternò); d) main portal of S. Antonio Abate church

(Mascalucia); e) S. Maria Annunziata church (Mompilieri); f) S. Maria della Catena church (Paternò). 

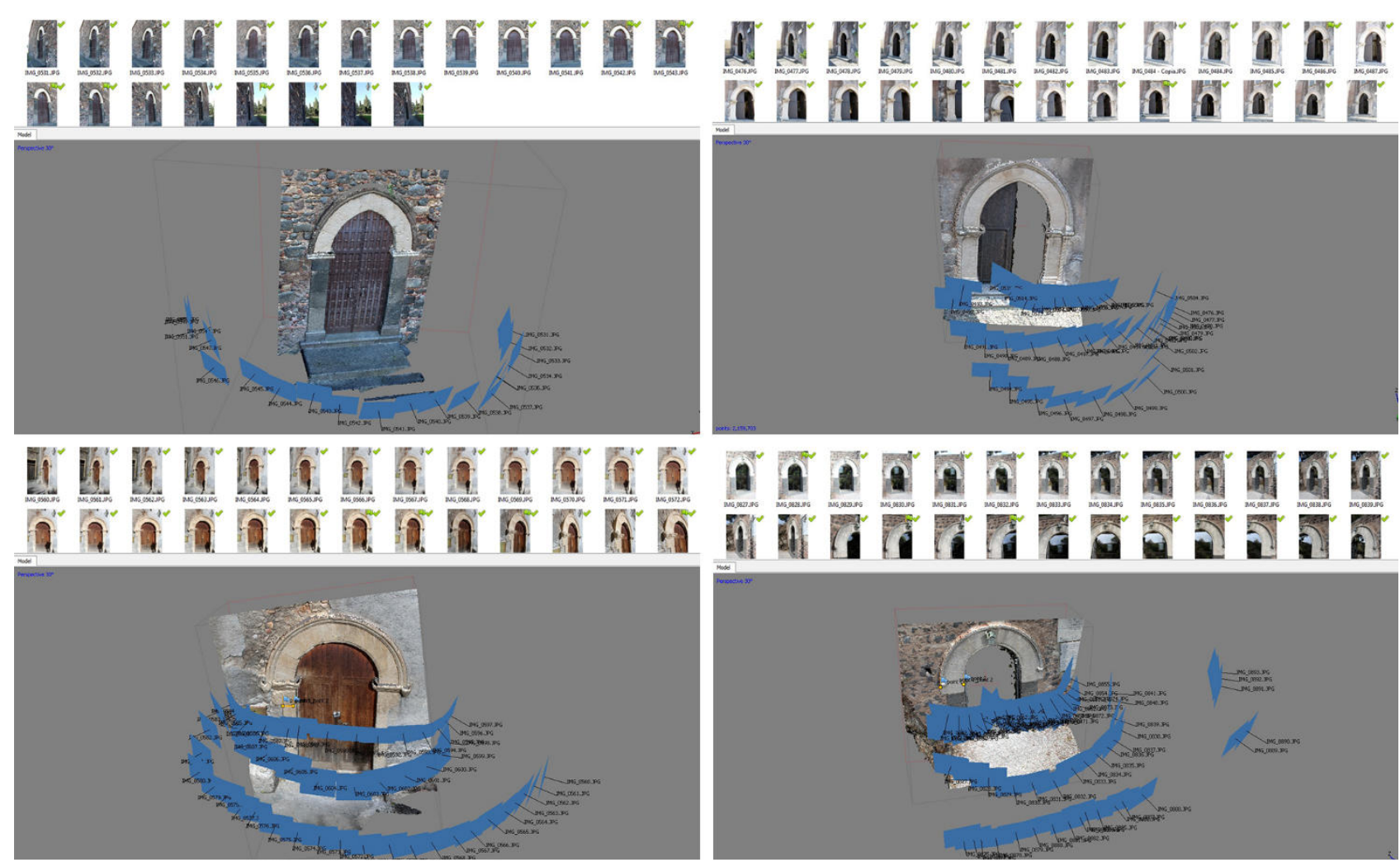

Figure 2. View of the datasets and image pose reconstruction

Among all the available portals, the following portals will be analyzed in detail:

- main and lateral portal of the Church of Sant'Antonio Abate in Mascalucia;

- main portal of church of Santa Maria di Josaphat in Paternò;

- main portal of the convent of San Francesco in Paternò;

- lateral portal of church of Santa Maria della Catena in Paternò (now entitled to Carmine);

- portal of church Santa Maria Annunziata in Mompilieri (Mascalucia).

As said, the applied methodology covers a full digital workflow to obtain H-BOMs of the identified architectural element starting from the 3D data acquisition to the modeling of the element in BIM environment.

\subsection{D data acquisition and processing}

The phase of the survey has provided for capturing image datasets, taking some direct measurements and Ground Control Point (GCP) indirect measurements through topographic instruments. For each model, the Ground Sampling Distance (GSD) media was verified, which allows to define the correct representation scale of the virtual $3 \mathrm{~d}$ model. The images were processed using Agisoft Photoscan digital photogrammetry software that provides the user with the ability to correctly set the $3 \mathrm{D}$ reconstruction parameters in terms of model accuracy and quality.

Reconstruction phase is divided into some steps: at the beginning the software produces a sparse point cloud derived from the 3D alignment of the images; then, a dense point cloud can be obtained: texture and mesh are also processed and associated to the dense point cloud (figure 2). Portal geometries have led to the choice of a high-quality reconstruction with the features shown in Table 1 . For each portal, 8 points were precisely detected using markers for homologous points to verify the accuracy of 3D reconstruction; in addition, this process permits to correctly scale the virtual models. The obtained point clouds have been exported in *.pts format so that they can be indexed and eventually cropped in Recap PRO, and then imported into Autodesk Revit 2017.

\subsection{Identification of the geometrical and stylistic feature}

As already said, the chosen portals belong to a historic period characterized by the Spanish domination of Sicily, from the end of $13^{\text {th }}$ century to the beginning of $16^{\text {th }}$ century, and are distinctive of the passage from the French gothic (Angevin domination) to the Aragonese Catalan gothic style.

\begin{tabular}{|c|c|c|c|c|c|}
\hline & $\begin{array}{c}\text { N. of } \\
\text { Images }\end{array}$ & Camera & $\begin{array}{c}\text { Resolu } \\
\text { tion }\end{array}$ & $\begin{array}{c}\text { Point Cloud } \\
\text { Photoscan }\end{array}$ & GSD \\
\hline $\begin{array}{c}\text { S. Maria della } \\
\text { Catena } \\
(2.19 \times 2.82 \mathrm{~m})\end{array}$ & 52 & $\begin{array}{c}\text { Canon EOS } \\
1200 \mathrm{D}\end{array}$ & $\begin{array}{c}3456 \mathrm{x} \\
5184\end{array}$ & 16.554 .432 & 0.7 \\
\hline $\begin{array}{c}\text { S. Maria di } \\
\text { Josaphat } \\
(3.46 \times 4.56 \mathrm{~m})\end{array}$ & 41 & $\begin{array}{c}\text { Canon EOS } \\
1200 \mathrm{D}\end{array}$ & $\begin{array}{c}3456 \mathrm{x} \\
5184\end{array}$ & 2.159 .703$. & 1.16 \\
\hline $\begin{array}{c}\text { S. Maria } \\
\text { Annunziata } \\
(2.71 \times 3.36 \mathrm{~m})\end{array}$ & 67 & $\begin{array}{c}\text { Canon EOS } \\
1200 \mathrm{D}\end{array}$ & $\begin{array}{c}3456 \mathrm{x} \\
5184\end{array}$ & 3.947 .703 & 0.88 \\
\hline $\begin{array}{c}\text { S. Antonio } \\
\text { Abate (main) } \\
(3.95 \times 4.06 \mathrm{~m})\end{array}$ & 91 & $\begin{array}{c}\text { Canon EOS } \\
1200 \mathrm{D}\end{array}$ & $\begin{array}{c}3456 \mathrm{x} \\
5184\end{array}$ & 6.267 .512 & 1.3 \\
\hline $\begin{array}{c}\text { S. Antonio } \\
\text { (lateral) } \\
(2.18 \times 2.33 \mathrm{~m})\end{array}$ & 41 & $\begin{array}{c}\text { Canon EOS } \\
1200 \mathrm{D}\end{array}$ & $\begin{array}{c}3456 \mathrm{x} \\
5184\end{array}$ & 4.583 .682 & 0.79 \\
\hline $\begin{array}{c}\text { S. Francesco } \\
(2.66 \times 3.96 \mathrm{~m})\end{array}$ & 21 & $\begin{array}{c}\text { Canon EOS } \\
1200 \mathrm{D}\end{array}$ & $\begin{array}{c}3456 \mathrm{x} \\
5184\end{array}$ & 8.617 .195 & 0.87 \\
\hline
\end{tabular}

Table 1. Summary of datasets of the point clouds derived from Image Based Modeling. 


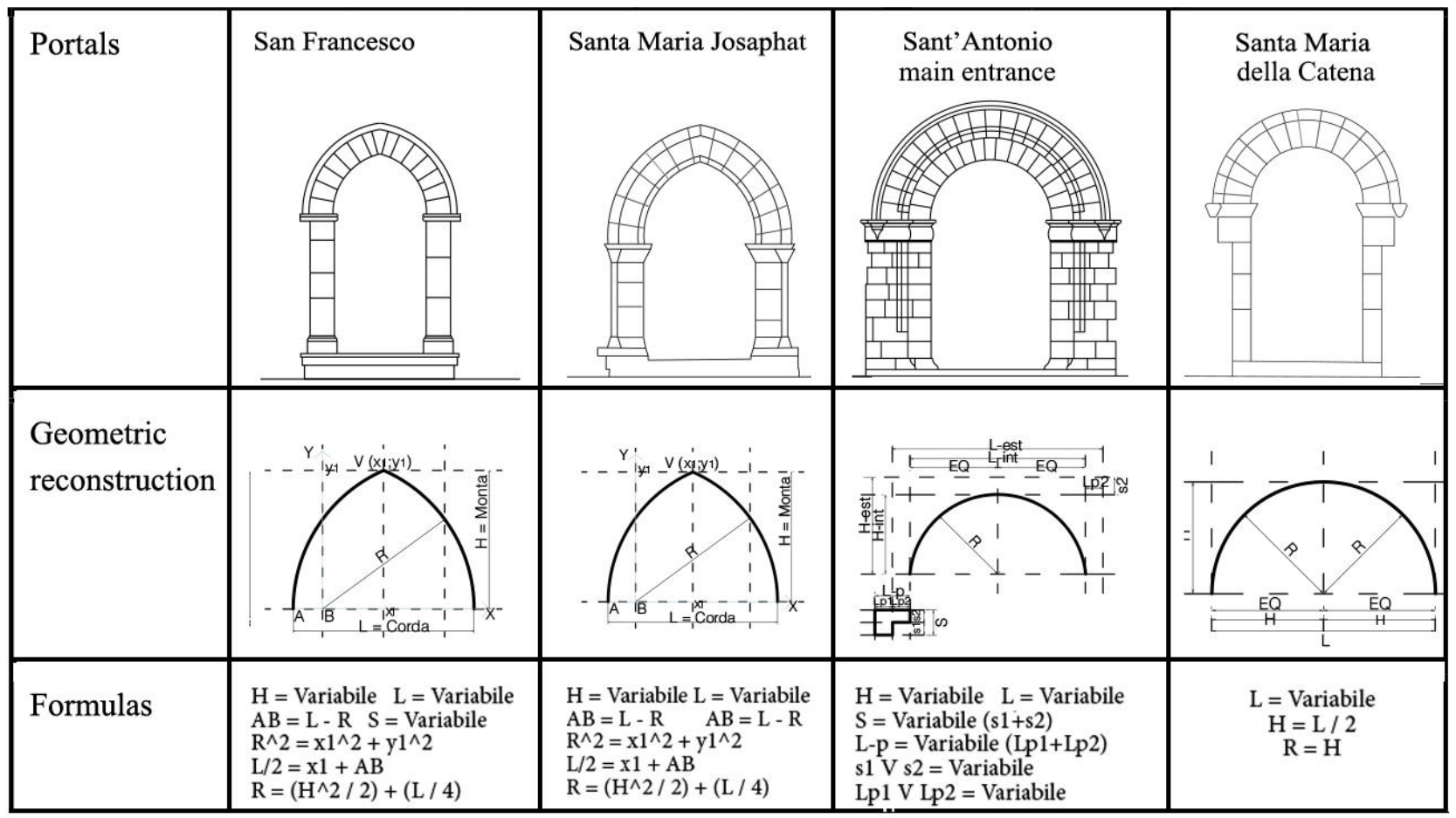

Figure 3. Geometrical and mathematical reconstruction of some studied portals.

The first three analyzed portals date back to the $14^{\text {th }}$ century. They are very simple, except for the main entrance of Santa Maria di Josaphat. They are composed by an arched structure (abutments and archivolt) enriched by a cornice that marks the springer line and are characterized by the use of a obtuse-angled pointed arch. In the case of the lateral portal of Sant'Antonio church, the archivolt is simply composed by the ashlars without any decoration, whilst in the case of Santa Maria di Josaphat and San Francesco it is concluded by a cordon. Furthermore, the use of two constructions materials is recognizable in the portal of San Francesco convent: white limestone for the archivolt and lava stone for the abutments and the cordon. The cutting of the ashlars of the archivolt, mostly guided by the two centers, is not so regular. The other three portals date back to $15^{\text {th }}$ - beginning of $16^{\text {th }}$ century and are expression of the mature application of Catalan - gothic stylistic features (figure 3).

Also in this case they are composed by an arched structure (abutments and archivolt) enriched by a cornice that marks the springer line and are characterized by the use of a semicircular arch with a simple archivolt crowned by a cordon which lies on corbels. For the portal of Sant'Antonio Abate e Santa Maria Annunziata we can highlight the combined use of two local construction materials (white limestone and lava stone). In particular, lavastone is used for the abutments, whilst white limestone for the springer cornice ashlar and the archivolt, this is due to the major easiness in the stone manufacturing to obtain well sculptured details. The cutting of the ashlars is directly linked to the center of the arch, and complies with the on-site laying adjustments (figure 4).

\subsection{Geometrical/metrological/modular study}

To carry out geometrical study of the portals it is mandatory to reason in accordance with design methodologies and anthropometric measurements used in the past. Usually not only in the project of a building but also in the proportioning of its architectural elements (openings) there was always a geometric proportional rule at the basis, which bound the individual parts to the whole. Some of these relationships are made explicit and known in the various treaties of Architecture (golden section, modular proportions, dynamic proportions, sacred section). In our case the identification of the geometrical rule that governs the structure of the portals has a dual purpose: 1) understanding if there is a recurrent geometrical rule for dimensioning the size of the portals; 2) finding the analytical/mathematical formula that parametrically describes such geometries.
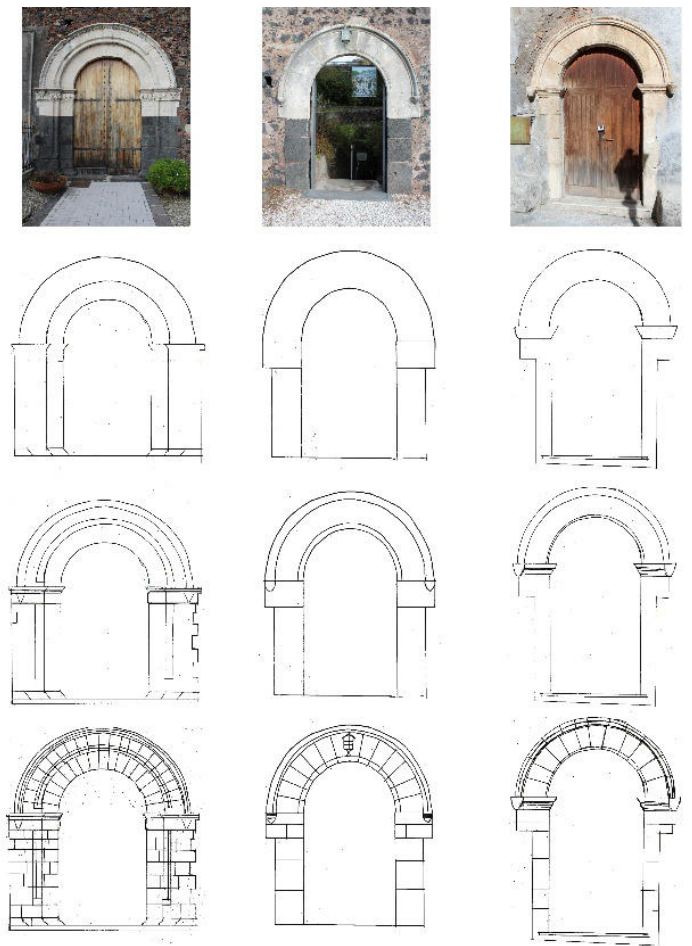

Figure 4. Catalan-Aragonese gothic portals dimension sketches: the main portal of S. Antonio Abate church in Mascalucia (on the left); b) S. Maria Annunziata church in Mompilieri (center);

S. Maria della Catena church in Paternò (on the right). 


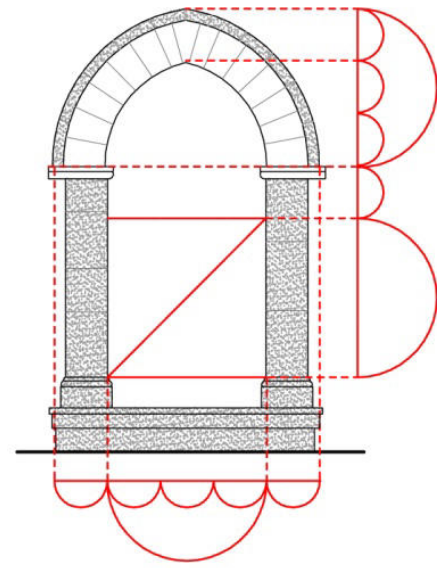

San Francesco

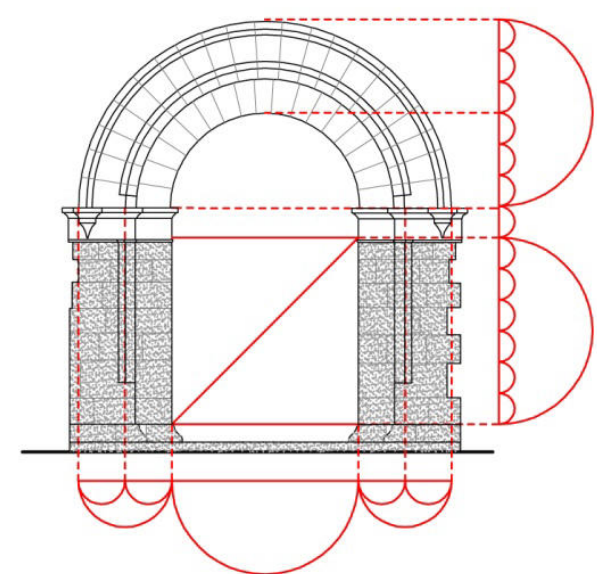

Sant'Antonio Abate main entrance

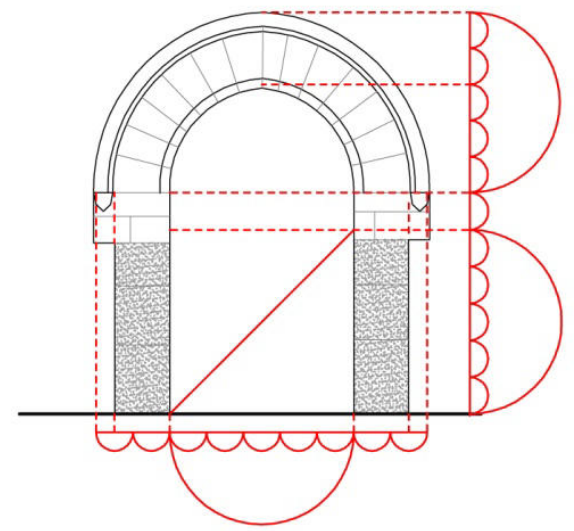

Santa Maria Annunziata

Figure 5. Graphical geometrical analysis of some studied portals.

The geometrical study highlights the presence of a regular modular grid based on the square and its sub-modules that give rhythm to the architectural composition.

Considering the vertical scan of the openings, they are framed in a square, then follows a horizontal zone (which corresponds to the springer cornice and the change of material from lavastone to white limestone) usually sub module of the side of the square with a ratio of $1 / 3,1 / 5,1 / 6$ then the arch and the archivolt usually are framed in another square.

As for the horizontal scan of the portals once again there is a relation between the breadth of the openings and the relative abutments which is a sub module of the width of the openings with a ratio of $1 / 2 ; 1 / 3,2 / 5$.

Figure 5 shows the results of the graphical analysis on San Francesco convent, Sant'Antonio main entrance and Santa Maria Annunziata portals.

Furthermore, the metrological analysis aimed at the verification of the obtained results with the metrical units used in the investigated period $\left(14^{\text {th }}-16^{\text {th }}\right.$ century), the palmo (equal to 0.2577 ) and the canna (equal to $2,062 \mathrm{~m}$, that is 8 palms) confirmed its use in the cutting of the ashlars of all the components of the portals.

\subsection{Identification of common and variant features}

The studies carried out in the previous steps allow for a first identification of common and variant features according to several aspects: dimensional, stylistic, geometrical and used construction materials.

The portals can be grouped in two sub-clusters, according to their geometrical features (potential presence of the obtuse pointed or circular arch) and used materials (white limestone or combined use of limestone and lava stone).

The structure of the portals is easily recognizable: it is an arched structure (obtuse pointed or circular arch) with abutments (in lava stone or white limestone), springer cornice (except for Santa Maria Annunziata) and an archivolt ended by a cordon and corbels.

Reasoning on the invariant and variant elements, we can assume that the arch spring cornice is not always present (as in the case of Santa Maria Annunziata), and in some cases the cordon profile is external in respect of the abutment line (Santa Maria Annunziata, San Francesco); furthermore, the cornice and cordon $2 \mathrm{D}$ profiles vary according to the creativity of the craftsmen.
Summarizing, also invariant can be described: the presence of a limestone archivolt ended by a cordon (extrusion along a curve path), the presence of lava stone/white limestone abutments (extrusion); the presence of a corbel, the use of limestone ashlar in correspondence of the arch springer; the variant elements are the $2 \mathrm{D}$ profiles of the cordon, the presence of arch springer cornice, the position of the 2D profile of the cordon (inside or outside the external jamb line).

\subsection{Historical Building Object Modeling}

Historical architecture knowledge-based approach is crucial for single architectural components recognition: the understanding of their links and relationships with the whole architectural building is crucial in order to achieve a proper classification and semantic decomposition of the architectural elements and the different components/details that form them.

In the modeling phase, the above mentioned geometric analysis have been taken into account: this allowed us to reason on the "portal" component, according to the various features identified. The resulting portals consists of assembling two-dimensional elements (parametric 2D profiles) and three-dimensional ones (corbels, steps, cornices, archivolts, stringcourses, etc..). To ensure maximum flexibility and allow future aggregations of different components. The nesting procedure family design was used to preserve hierarchies and relationships previously identified.

Using measurements derived from the uninterpreted metric data base (point cloud), it was possible to associate parameters to the individual components by using formulas, proportions, and equations that control the individual geometric variables that characterize the case study.

The most widely used family categories are surface-based metric generic models that are loaded and assembled in a metric door family template. Within the same family, the empty elements (i.e. the shape of the empty that characterizes the access) have been parameterized, through the use of Boolean operations by subtracting solids. The subtraction solid will allow to obtain the rough hole in the wall that hosts the portal.

\subsection{Setting of the different LoD (Levels of Development)}

One of the advantages of BIM modeling is the ability to manage graphical and information content at the same time.

In this respect, the recent Italian legislation on Public Works is partly in line with the norms and international guidelines. More 
in detail, the use of BIM in restoration projects related to cultural assets safeguarded by the Codice Urbani ("Urbani code" for cultural heritage and landscape, Italian Decree-Law ${ }^{\circ}$ 42/2004) is currently under discussion by the Commission appointed by the MiBACT (Italian Ministry of cultural heritage, cultural activities, and tourism) legislation office, which must proceed to draft a Ministerial Decree that will complete the part related to cultural heritage of the framework for the new Codice dei Contratti Pubblici (code for public contracts, Decree-Law $n^{\circ}$ 50/2016)

In addition, the new Italian UNI 11337:2017 "Digital management of information processes for construction" also defines the various Level of Development (LoD) for restoration, by specifying the difference between LoG (Level of Geometry, referred to the definition of purely graphical content) and LoI (Level of Information, which refers to the alphanumeric database that can be associated with the modeled components. Basically, three different levels of detail (associated with different representation scales depending on the metric accuracy and the level of reliability of the acquired data) were identified, as initially outlined through the dimensioned sketches (figure 4, figure 6). Paper schemes was then taken back in a digital environment by selecting, for each individual part of the decorative apparatus, the graphic representation (2D and / or 3D) congruent with the different levels of LoG.
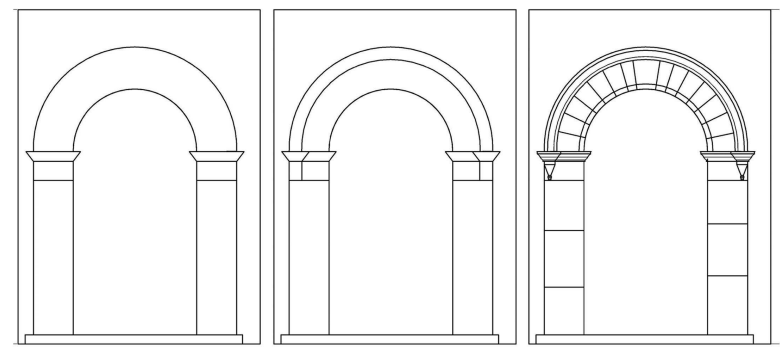

Figure 6. Example of digital family set up according to different levels of Graphic Detail (LOG) modeled in a BIM environment. The case study of S. Maria delle Grazie church in Misterbianco (elevation view).

\subsection{In-depth analysis of LOI setting up}

As above described, the alphanumeric attributes associated with the different modeled components constitute the added value of the BIM-type information models: the benefit consists in the ability to associate new parameters that populate the database by a great deal of other information, such as data from collection of old metric surveys available in specific historical archives, from ancient and more recent pictures, from descriptions and technical features of the material that could be used to establish past and future interventions, from the description of the state of conservation of the materials and the interventions needed to restore the building.

In order to reuse the list of new parameters for this specific activity, it is necessary to use shared parameters: doing that, the information asset is not specifically linked to a particular object or component but has transversal and replicable use over time.

\section{RESULTS}

Given the great geometric complexity of the case studies identified, as well as the extreme formal variety of the portals identified, it is not possible to attribute different instances to a single parameterized component. However, the parameterization of the individual parts that make up the portal guarantees flexibility: to distinguish between Gothic pointed arches and rounded ones, regardless of the height and width dimensions of the arch itself (variable). This guarantees the generation of multiple instances according to multiple dimensional values.

The various extrusions based on the path, (cornices, string courses) are strongly influenced by the typology of moldings: fillets, straight and reverse cyma moldings, echinus and tore. From a technical point of view, they constituted by 2D profile families (reusable, project after project) and model lines that define the extrusion path, directly associated with the geometry that characterizes the portal family. The combination of individual moldings, parameterized in detail in the various profile families described above, generates that variety that characterizes the decorative structures of Catalan and Aragonese architectures of that period (figure 7).

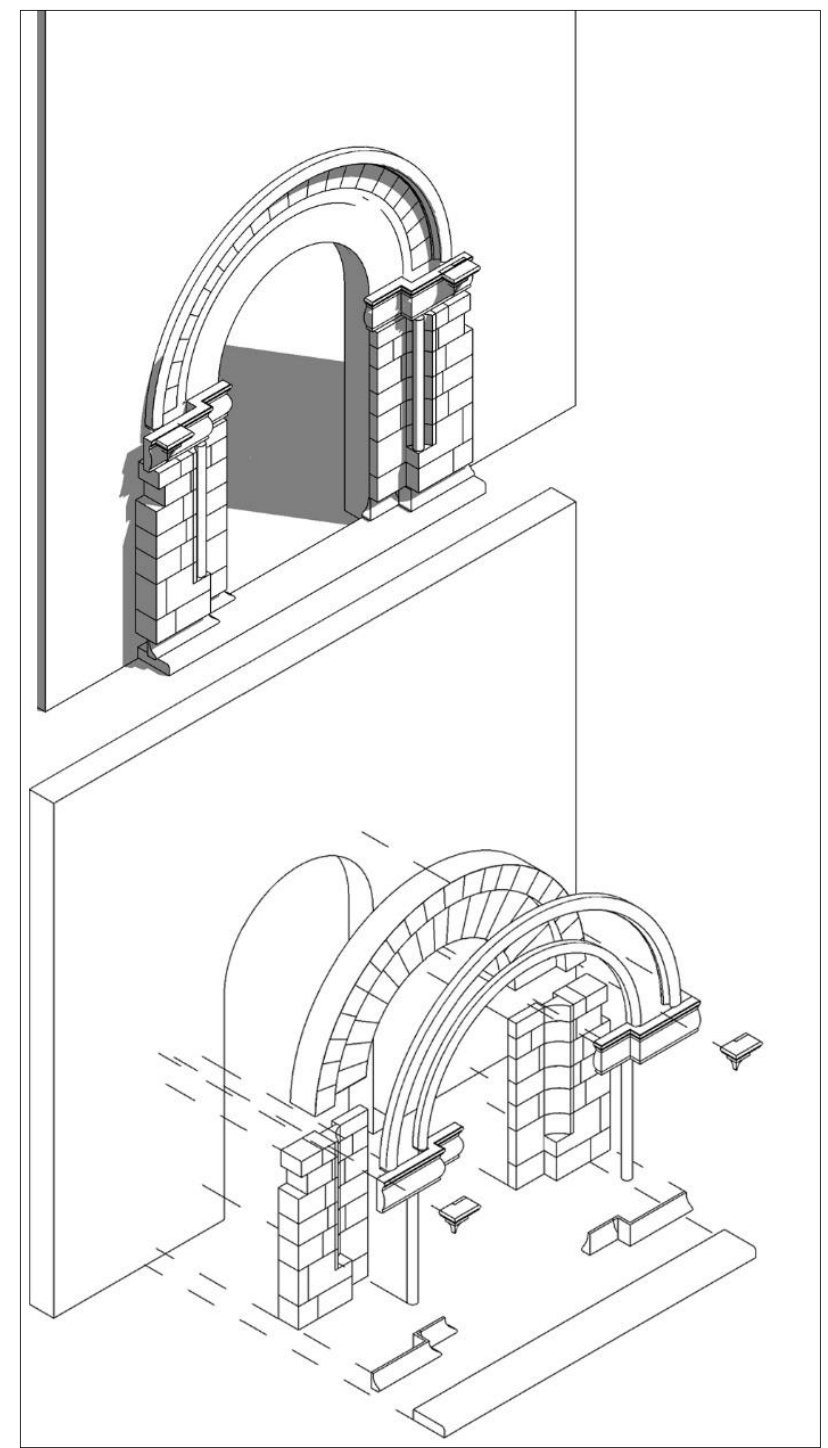

Figure 7. Exploded axonometry of the main portal of S. Antonio Abate church (Mascalucia). The portal can be divided into several parts that constitute the atoms of the historical architecture.

Other elements have been directly modeled in 3D: piers, steps, corbels: they can also be reused in different scenarios: through the combination of nested families and shared parameters it is possible to control the geometric variables from the portal family to further confirm the geometric flexibility which 
guarantees the identified operational strategy. More the molding's library and the decorative apparatus will be rich, easier and quicker in the future will be the grouping of individual parts (figure 8 ).
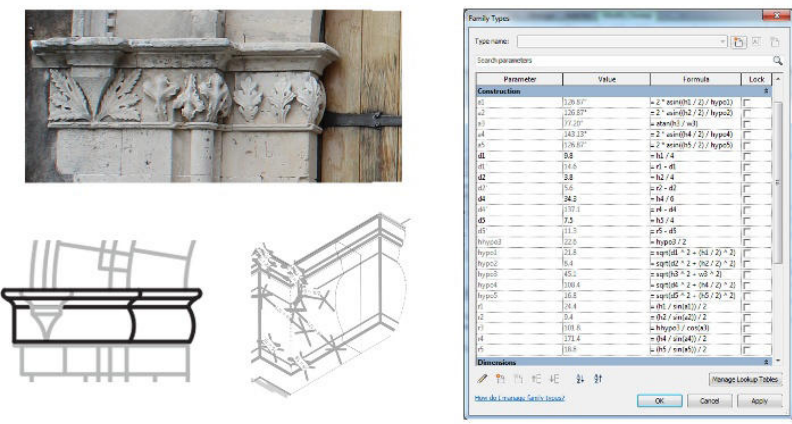

Figure 8. Springer cornice of S. Antonio Abate church (Mascalucia). From the picture to the 2D and 3D representation, up to the complete geometric control through the insertion of parametric variables.

\section{CONCLUSION AND FUTURE ACTIVITIES}

This research work is related to an international research topic in the field of 3D modeling aimed at evaluating the performance of BIM approach for graphic and alphanumeric representation of Cultural Heritage.

Modeling an historic building involves the creation of parametric objects library starting from data survey. The primary purpose of the research is the translation of these information into a parametric model, through the definition of a proper methodology that can be used for two main purposes: firstly, we need to evaluate if the work is useful to point out some geometric invariants of an architecture that is not classified and explained by historical treatises. In this respect, spreadsheets have been associated with the specific dimensional values of each single portal: this kind of processing can be related to the geometric interpretation in order to make the recognition of some invariants easier. A future development is to relate formulas and measures with algorithms typical of VPL (Visual Programming Language) applications that relate to BIM platforms more and more efficiently.

Secondly, this work would allow us to rationalize the work of arranging object libraries that do not exist. In particular, the amount of molding families could be rationalized if conceived as aggregation of simple parts. Thus the complex moldings will be obtained as the result of the aggregation of the simplest ones. By doing so, the number of designed families will be rationalized.

According to that, the heritage conservation process launched by the digital workflow could be used for the restoration process: a sort of info-graphic database: a collector of a huge amount of heterogeneous data made available for all the professionals involved into the knowledge process. Finally, the virtual model can be used to catalogue and record libraries of semantic aware object that can be shared with the Scientific Community. This is useful both to constitute libraries of historical objects and to prepare the field for future automatic recognition of point cloud portions, that can be designed to optimize the modeling phase of unconventional shapes, that nowadays is a very time-consuming procedure.

\section{ACKNOWLEDGMENTS}

The authors would like to thank Simone Del Giudice and Luigi Preti for the valuable contribution to the definition of the iconographic apparatus available in this work.

\section{REFERENCES}

Andreozzi L., (ed), 2005. Verso un repertorio dell'architettura catalana. Architettura catalana in Sicilia. Province di Caltanissetta, Catania, Enna, Messina, Palermo. Vol 3, Aracne editrice, Rome.

Andreozzi L., (ed), 2007. L'architettura di età aragonese nell'Italia centro-meridionale, Verso la costituzione di un sistema informativo territoriale documentario iconografico, L'architettura di età aragonese nel Val Demone, vol 5 Aracne editrice, Rome.

Apollonio F. I., Gaiani, M., Sun, Z. 2012. BIM-based modeling and data enrichment of classical architectural buildings. SCIRES-IT 2(2), 41-62.

Biagini, C., Capone, P., Donato, V., Facchini N. 2016. Towards the BIM implementation for historical building restoration sites. Automation in Construction 71, 74-86.

Bonsma, P., Bonsma, I., Ziri, A. E., Parenti, S., Martín Lerones, P., Maietti, F., Medici, M., Turillazzi, B., Iadanza, E., 2016. INCEPTION Standard for Heritage BIM Models Digital Heritage. In: Progress in Cultural Heritage: Documentation, Preservation, and Protection, Springer International Publishing, pp. 590-599.

Chiabrando, F., Spanò, A., 2013. Points Clouds generation using TLS and Dense-Matching techniques. A test on approachable accuracies of different tools. ISPRS Annals of the Photogrammetry, Remote Sensing and Spatial Information Sciences, II, pp. 2-6.

Chiabrando F., Lo Turco M., Santagati C., 2017. Digital invasions: from point clouds to historical building object modeling (H-BOM) of a Unesco WHL site. International Archives of the Photogrammetry, Remote Sensing and Spatial Information Sciences, pp. 171-178.

Clarke G., Crossley, P. 2000. Architecture and Language: Constructing Identity in European Architecture, Cambridge University Press, Cambridge, pp. 1000-1650.

Dore, C., Murphy, M., 2014. Semi-automatic generation of asbuilt BIM facade geometry from laser and image data, ITcon 19, 20-46 (2014).

Galizia, M., Inzerillo, L., Santagati C., 2015. Heritage e technology: novel approaches to $3 \mathrm{D}$ documentation and communication of architectural heritage. HERITAGE and TECHNOLOGY Mind Knowledge Experience - Le vie dei Mercanti XIII Forum Internazionale di Studi. La Scuola di Pitagora, Napoli, pp. 686-695.

Garagnani S., Manferdini M., 2013. Parametric accuracy: building information modeling process applied to the cultural heritage preservation, Int. Arch. Photogramm. Remote Sens. Spatial Inf. Sci. XL(5/W1), 87-92.

Hichri, N., Stefani, C., De Luca, L., Veron, P., Hamonet, G., 2013. From Point Cloud To BIM: a Survey of Existing Approaches. International Archives of the Photogrammetry, Remote Sensing and Spatial Information Sciences, XL-5/W2, 
pp. 343-348.

Inzerillo, L., 2008. Il Gotico chiaramontano, aragonese e catalano nella Sicilia Occidentale: monofore, bifore, trifore e cappelle interne. Caracol, Palermo.

Inzerillo, L., Santagati, C., 2013. Using dense stereo matching techniques in survey. Disegnare Idee Immagini, 47/2013, pp. 82-91.

Kersten, T., Lindstaedt, M., 2012. Automatic 3D object reconstruction from multiple images for architectural, cultural heritage and archaeological applications using open-source software and web services, Photogramm. Fernerkundung Geoinf. 2012(6), 727-740.

Lo Buglio, D., De Luca, L. 2012. Representation of architectural artifacts: definition of an approach combining the complexity of the $3 \mathrm{~d}$ digital instance with the intelligibility of the theoretical model. SCIRES-IT SCIentific RESearch and Information Technology, Vol 2, Issue 2, 63-76.

Lo Turco, M., Mattone, M., Rinaudo, F. 2017. Metric survey and BIM technologies to record decay conditions. International Archives of the Photogrammetry, Remote Sensing and Spatial Information Science, vol. XLII-5 n. W1, pp. 261-268.

Murphy, M., McGovern, E., Pavia, S., 2013. Historic Building Information Modelling - Adding intelligence to laser and image based surveys of European classical architecture. ISPRS J Photogramm Remote Sens, 76, pp. 89-102.

Phillips, S. C., Walland, P. W., Modafferi, S. Dorst, L., Spagnuolo, M.; Catalano, C. E., Oldman, D., Tal, A., Shimshoni, I., Hermon, S., 2016. GRAVITATE:Geometric and Semantic Matching for Cultural Heritage Artefacts. Catalano, E.C., De Luca, L., (eds) Eurographics Workshop on Graphics and Cultural Heritage. 199-202

Quattrini, R., Malinverni, E. S., Clini, P., Nespeca, R., Orlietti, E., 2015. From TLS to HBIM: high quality semantically-aware 3D modeling of complex architecture. International Archives of the Photogrammetry, Remote Sensing and Spatial Information Sciences, 40(5/W4), pp. 367-374.

Santagati, C., Lo Turco, M., 2016. From structure from motion to historical building information modeling: populating a semantic-aware library of architectural elements. J. Electron. Imaging 26(1), 011007.

Tang, P. Huber, D., Akinci B. Lipman, R. Lytle, A. 2010. Automatic reconstruction of as-built building information models from laser-scanned point clouds: a review of related techniques, Autom. Constr. 19, 829-843. 